Research Article

\title{
Cytogenetic analysis of three species of Pseudacteon (Diptera, Phoridae) parasitoids of the fire ants using standard and molecular techniques
}

\author{
Mónica G. Chirino ${ }^{1}$, Patricia J. Folgarait ${ }^{1}$, Lawrence E. Gilbert ${ }^{2}$, Silvia Lanzavecchia ${ }^{3}$ and Alba G. Papeschi ${ }^{4}$ \\ ${ }^{1}$ Centro de Estudios e Investigaciones, Universidad Nacional de Quilmes, Bernal, Buenos Aires, Argentina. \\ ${ }^{2}$ Brackenridge Field Laboratory, University of Texas, Austin, USA. \\ ${ }^{3}$ Instituto de Genética, INTA, Castelar, Buenos Aires, Argentina. \\ ${ }^{4}$ Laboratorio de Citogenética y Evolución, Facultad de Ciencias Exactas y Naturales, Universidad de \\ Buenos Aires, Buenos Aires, Argentina.
}

\begin{abstract}
Pseudacteon flies, parasitoids of worker ants, are being intensively studied as potentially effective agents in the biological control of the invasive pest fire ant genus Solenopsis (Hymenoptera: Formicidae). This is the first attempt to describe the karyotype of $P$. curvatus Borgmeier, $P$. nocens Borgmeier and $P$. tricuspis Borgmeier. The three species possess $2 \mathrm{n}=6$; chromosomes I and II were metacentric in the three species, but chromosome pair III was subtelocentric in $P$. curvatus and $P$. tricuspis, and telocentric in $P$. nocens. All three species possess a $C$ positive band in chromosome II, lack $\mathrm{C}$ positive heterochromatin on chromosome I, and are mostly differentiated with respect to chromosome III. P. curvatus and $P$. tricuspis possess a $C$ positive band, but at different locations, whereas this band is absent in $P$. nocens. Heterochromatic bands are neither AT nor GC rich as revealed by fluorescent banding. In situ hybridization with an $18 \mathrm{~S}$ rDNA probe revealed a signal on chromosome II in a similar location to the $\mathrm{C}$ positive band in the three species. The apparent lack of morphologically distinct sex chromosomes is consistent with proposals of environmental sex determination in the genus. Small differences detected in chromosome length and morphology suggests that chromosomes have been highly conserved during the evolutionary radiation of Pseudacteon. Possible mechanisms of karyotype evolution in the three species are suggested.
\end{abstract}

Key words: Pseudacteon, karyotype evolution, C-banding, fluorescent banding, FISH.

Received: December 19, 2008; Accepted: May 4, 2009.

\section{Introduction}

The Phoridae, one of the most diverse families within the order Diptera, includes more than 26,000 min species, varying in life style from scavengers and predators to parasitoids (Disney, 1994; Gilbert and Jervis, 1998). The phorid genus Pseudacteon Coquillet are parasitoids, most of the species parasitizing Solenopsis Westwood fire-ants (Hymenoptera: Formicidae) (Disney, 1994). Pseudacteon flies are solitary parasitoids (Disney, 1994). The females inject a single egg into each worker ant, the third larval instar of which migrating into and later pupating within the host's cephalic capsule (Porter et al., 1995; Porter, 1998).

Solenopsis has a cosmopolitan distribution (Disney, 1994; Patrock et al., 2009). In South America, 22 Pseudacteon species have been reported as parasitizing fire-ants of the Solenopsis saevissima complex (Porter and Pesquero, 2001; Brown et al., 2003; Folgarait et al., 2005b;

Send correspondence to Mónica G. Chirino. Centro de Estudios e Investigaciones, Universidad Nacional de Quilmes, Roque Saenz Peña 352, B1876BXD Bernal, Buenos Aires, Argentina. E-mail: mchirino@unq.edu.ar.
Calcaterra, 2007; Kronforst et al., 2007). Currently, these flies are used as biological control agents against Solenopsis invicta Buren and $S$. richteri Forel fire-ants, native to Argentina (Mescher et al., 2003; Ross et al., 2008) and exotic pests in the United States (Porter et al., 2004; Thead et al., 2005; Morrison and Porter, 2006).

Despite numerous studies on the life-history traits of the genus Pseudacteon, including apparent environmental sex-determination in some species, cytogenetic studies are lacking. Dipteran species generally possess low diploid chromosome numbers, these ranging from $2 \mathrm{n}=4$ to 20 , with modal numbers at 6 and 8 (due to several families of "lower" Diptera i.e. SO Nematocera) and 12 (with many species of the SO Brachycera and belonging to calyptrate and acalyptrate families) (White, 1973). Almost all species of Sarcophagidae and Calliphoridae (SO Brachycera, superfamily Oestroidea) have $2 \mathrm{n}=12$ with a pair of sex chromosomes XY (Parise-Maltempi and Avancini, 2000; 2001). In the family Drosophilidae as a whole (SO Brachycera, superfamily Acalyptrata) the primitive chromosome number appears to be $2 n=12$ with five pairs of 
long acrocentric chromosomes (including the sex chromosome pair XY) and a small dot-like pair. Reduction in chromosome number has occurred many times independently by fusion of these elements (White, 1973). Many derived sex chromosome systems have been described and the evolutionary mechanisms of sex chromosome differentiation has been analyzed in Drosophila species (Steinemann and Steinemann, 2005). In Muscidae (SO Brachycera, superfamily Muscoidea) most species also possess $2 \mathrm{n}=12$ with $\mathrm{XY}$ sex chromosomes in the male. However, muscid species have been described with $2 \mathrm{n}=10$ chromosomes and lacking differentiated sex chromosomes (Parise-Maltempi and Avancini, 2001). In Phoridae (SO Brachycera, superfamily Phoroidea), Megaselia scalaris Loew and $M$. spiracularis Schmitz, the only 2 species that have been studied cytogenetically, possess the diploid number $2 \mathrm{n}=6$, with 2 metacentric and 1 telocentric chromosome pairs. They do not possess heteromorphic sex chromosomes and sex is determined by a single Maleness factor that can be located in any of the three linkage groups (Mainx, 1964; Traut and Willhoeft, 1990).

In order to evaluate whether the well-marked differences among $P$. curvatus Borgmeier, P. nocens Borgmeier and $P$. tricuspis Borgmeier in size, morphology, behavior and phylogenetic relations are also reflected in their karyotypes, our aim was to describe the karyotype of these species by using standard and molecular cytogenetic techniques. Descriptive values of the karyotype, heterochromatin content and distribution, and the location of nucleolus organizer regions (NORs) were analyzed. A comparative analysis of cytogenetic results also provided information on the possible karyotype evolution within the genus. Furthermore, we analyzed the presence of differentiated sex chromosomes, since it has been suggested, in the case of other species in the genus Pseudacteon, that sex determination is related to host size, and thus could be environmentally determined (Morrison et al., 1999).

\section{Material and Methods}

\section{Fly rearing}

Experiments were carried out between August, 2006 and November, 2007. Pseudacteon species were reared in colonies of $S$. invicta ants collected near Mercedes, Corrientes province $\left(29^{\circ} 47^{\prime} \mathrm{S}, 58^{\circ} 03^{\prime} \mathrm{W}\right)$. Adult males and females of $P$. curvatus were captured in the Reserva Ecológica Costanera Sur (RECS), Buenos Aires province $\left(34^{\circ} 37^{\prime} \mathrm{S}, 58^{\circ} 22^{\prime} \mathrm{W}\right)$, those of $P$. tricuspis near San Javier, Santa Fe province (30 $\left.58^{\prime} \mathrm{S}, 59^{\circ} 94^{\prime} \mathrm{W}\right)$, and those of $P$. nocens from Mercedes, Corrientes province $\left(29^{\circ} 11^{\prime} \mathrm{S}\right.$, $\left.58^{\circ} 5^{\prime} \mathrm{W}\right)$, all in Argentina.

\section{Slide preparation}

Different oviposition assays were performed in the lab following the same methodology used by Chirino et al.
(2009). The "attacked" ants were placed in a rearing room at $28 \pm 1{ }^{\circ} \mathrm{C}$ with a $12: 12$ (light: darkness) photoperiod and $80 \pm 10 \%$ RH.

In Diptera, cytogenetic analyses are mainly carried out with third instar larvae or early pupae (Traut and Willhoeft, 1990; Cevallos and Nation, 2004). Since development in Pseudacteon takes place within its host (Porter et al., 1995), it is difficult to obtain larvae at the appropriate developmental stages for cytogenetic studies. Thus we dissected pupae of 3-5 days, which lacked differentiated tissues, but showed high mitotic indices.

Since the females of $P$. tricuspis and $P$. nocens emerge from larger ant-heads than males, parasitized worker heads were measured and developed pupae were classified as either potential females or males. In contrast, both sexes of $P$. curvatus develop in similar sized hosts, so they could not be classified by sex (Morrison et al., 1997; Folgarait et al., 2006).

Pseudacteon pupae were dissected in a saline solution, swollen in a hypotonic solution $(0.075 \mathrm{M} \mathrm{KCl})$ for 10-20 min, and fixed for 15-30 min in freshly prepared Carnoy fixative (ethanol: chloroform: acetic acid, 6:3:1). Slides were prepared according to Traut (1976).

\section{Chromosome morphology}

Suitable cells at the mitotic prometaphase were selected and the mean descriptive values of the karyotype were calculated using information obtained from at least 3 cells per slide for each individual of each species analyzed $(20.78 \pm 9.76$ cells $)$. Each slide represented different individual pupae. Mitotic prometaphases were obtained from $P$. tricuspis pupae (17 males and 24 females); from $P$. nocens pupae (27 males and 21 females), and 35 specimens of $P$. curvatus. Slides were stained with the fluorescent dye DAPI (Rebagliati et al., 2003) for morphological studies. The nomenclature of Levan et al. (1964) was used to describe chromosome morphology.

\section{Banding techniques}

Heterochromatin content and distribution was analyzed by means of the $\mathrm{C}$-banding technique and sequential DAPI and $\mathrm{CMA}_{3}$ banding. C-bands were performed according to Sumner (1972) with slight modifications. Slides were hydrolyzed in $\mathrm{HCl} 0.2 \mathrm{~N}$ at room temperature for $15 \mathrm{~min}$, briefly washed in distilled water and then incubated at room temperature for $35 \mathrm{~min}$ in a $5 \% \mathrm{Ba}(\mathrm{OH})_{2}$ solution. Slides were thoroughly washed in tap water for $1 \mathrm{~min}$ and incubated for $1 \mathrm{~h}$ in $2 \mathrm{XSSC}$ at $60^{\circ} \mathrm{C}$. After washing in distilled water, the slides were stained with DAPI (Rebagliati et al., 2003), since band resolution improves when pretreated slides are stained with DAPI instead of Giemsa. Fluorescent staining with $\mathrm{GC}$ specific chromomycin $\mathrm{A}_{3}$ $\left(\mathrm{CMA}_{3}\right)$ and AT specific 4'6- diamidino-2- phenylindole (DAPI) was carried out according to Rebagliati et al. (2003). 
For location of NORs, Ag-NOR staining was applied according to Howell and Black (1980). Fluorescent in situ hybridization (FISH) with $18 \mathrm{~S}$ rDNA was also undertaken.

\section{Fluorescence in situ hybridization}

Unlabelled $18 \mathrm{~S}$ rDNA probes were generated by PCR, using primers described by Fuková et al. (2005) and sequenced using an Automated Sequencer ABI 3100 (DNA Sequencer, PE, Applied Biosystems), thereby confirming their being a section of $18 \mathrm{~S}$ rDNA of Ceratitis capitata (Weidemann) (Diptera: Tephritidae). PCR was done in a Mastercycler $^{\mathbb{B}}$ Gradient Eppendorf thermal cycler (Eppendorf AG, Hamburg, Germany). Reactions were carried out with template genomic DNA extracted from $C$. capitata by standard procedure according to Baruffi et al. (1995). The PCR product showed a single band of about $900 \mathrm{bp}$ on a $1 \%$ agarose gel. The band was recovered from the gel and purified by using Wizard SV gel and PCR clean up (Promega). The rDNA probe was labeled by nick translation with biotin 14-dUTP (BioNick Labeling System, Invitrogen Life Technologies Inc., Buenos Aires , Argentina). FISH with a biotinylated probe was carried out as described by Sahara et al. (1999) with several modifications as described by Fuková et al. (2005). Hybridization signals were detected with streptavidin-Cy3 conjugate (Sigma, Saint Louis, USA). The preparations were counterstained with $0.5 \mu \mathrm{g} / \mathrm{mL}$ DAPI in PBS, $1 \%$ Triton X-100, and mounted in anti-fade (Vectashield Mounting Medium, Vector Laboratories, Inc., Burlingame, USA).

\section{Photographs}

Preparations were observed in a Leica DMLB epifluorescence microscope. Black-and-white images of chromosomes were recorded with a CCD camera (Leica DFC350 FX, Leica IM50 Version 4.0, Leica Microsystems Imaging Solutions Ltd. Cambridge, UK) separately for each fluorescent dye. Images were pseudocolored (light blue for DAPI and red for $\mathrm{Cy} 3$ ), and, when necessary, superimposed with the aid of AdobePhotoshop version 6.0.

\section{Statistical analysis}

The following chromosome measurements were performed with MicroMeasure for Windows, version 3.3: centromeric index CI (length of short arm as a percentage of the whole chromosome), arm ratio $\mathrm{r}$ (relationship between the long and the short arms of each chromosome), relative length \% (length of a chromosome as a percentage of the total chromosome length), and total chromosome length - TCL (the sum of the lengths of all the chromosomes of the complement). Comparisons of data within and between species were undertaken by analyses of variance (ANOVA), adjusted by the Bonferroni method. Statistical comparisons were done using the STATISTIX Program (Analytic Software 1998, Tallahassee, FL).

\section{Results}

Analysis of mitotic chromosomes of the pupae of Pseudacteon tricuspis, P. curvatus and $P$. nocens revealed a $2 \mathrm{n}=6$ diploid number (Figure $1 \mathrm{a}-\mathrm{b}$ ). Chromosome pairs I and II were metacentric in the three species, but chromosome pair III was subtelocentric in $P$. tricuspis and $P$. curvatus, and telocentric in $P$. nocens (Table 1). Neither $P$. tricuspis nor $P$. nocens possessed a distinguishable heteromorphic pair in potential males or females $(t=0.43$, $d f=39, \mathrm{p}=0.67$ for $P$. tricuspis and $t=0.07, d f=46$, $\mathrm{p}=0.95$ for $P$. nocens, 2-tailed $t$-Test). The three species did differ in total chromosome length (TCL) $\left(F_{2,99}=2.38\right.$, $\mathrm{p}=0.0453)$ which was higher in $P$. curvatus, lower in $P$. nocens and intermediate in $P$. tricuspis (Table 2). Chromosome I in $P$. nocens was relatively larger than in P. tricuspis
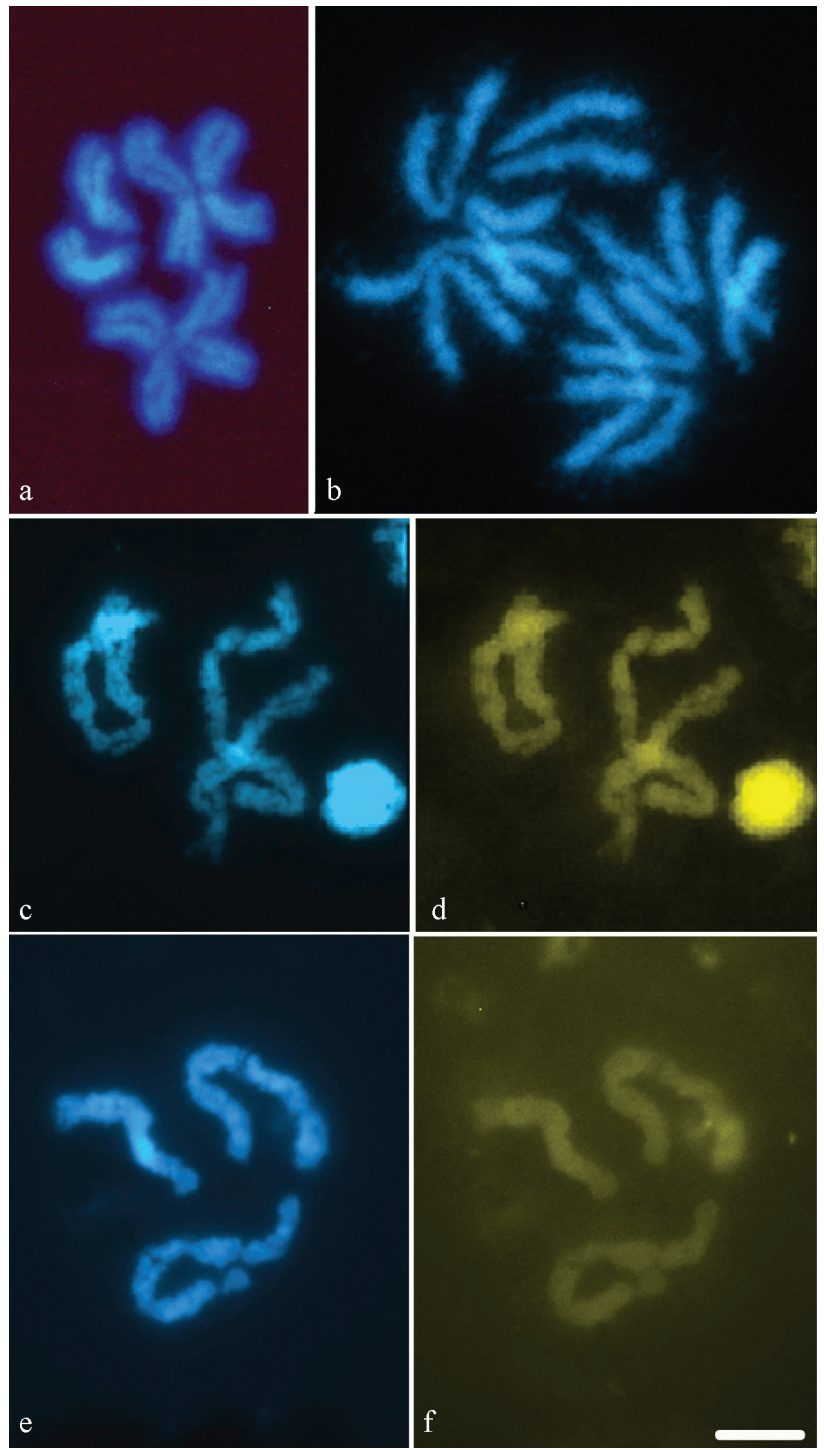

Figure 1 - Cells in the mitotic metaphase (a) and anaphase (b) of $P$. curvatus stained with DAPI. Fluorescent banding with DAPI (c,e) and $\mathrm{CMA}_{3}(\mathrm{~d}, \mathrm{f})$ in $P$. curvatus (c-d) and P. tricuspis (e-f). Bar $=10 \mu \mathrm{m}$. 
Table 1 - Comparison of the somatic complement of the Pseudacteon species analyzed. \%: relative length, r: arm ratio, CI: centromeric index, N: number of slides analyzed.

\begin{tabular}{lcccccc}
\hline \multicolumn{7}{l}{ Pseudacteon curvatus } \\
\hline Chromosomes & Average length $(\mu \mathrm{m})^{1}$ & $\%{ }^{1}$ & $\mathrm{r}$ & $\mathrm{CI}$ & Classification & $\mathrm{N}$ \\
\hline I & $47.11 \pm 17.53 \mathrm{a}$ & $19.96 \mathrm{a}$ & $1.14 \pm 0.10$ & 46.87 & $\mathrm{~m}$ & \\
II & $42.19 \pm 14.89 \mathrm{a}$ & $17.75 \mathrm{~b}$ & $1.15 \pm 0.09$ & 46.63 & $\mathrm{~m}$ & 35 \\
III & $30.01 \pm 12.14 \mathrm{~b}$ & $12.29 \mathrm{c}$ & $3.99 \pm 0.89$ & 21.18 & $\mathrm{st}$ & \\
\hline Pseudacteon tricuspis & & & & & \\
\hline Chromosomes & Average length $(\mu \mathrm{m})$ & $\%$ & $\mathrm{r}$ & $\mathrm{CI}$ & Classification & $\mathrm{N}$ \\
\hline I & $44.69 \pm 11.14 \mathrm{a}$ & $19.88 \mathrm{a}$ & $1.20 \pm 0.17$ & 45.78 & $\mathrm{~m}$ & \\
II & $40.43 \pm 9.26 \mathrm{a}$ & $18.07 \mathrm{~b}$ & $1.18 \pm 0.16$ & 46.20 & $\mathrm{~m}$ & 41 \\
III & $27.20 \pm 7.77 \mathrm{~b}$ & $12.05 \mathrm{c}$ & $5.20 \pm 0.74$ & 14.53 & $\mathrm{st}$ & \\
\hline Pseudacteon nocens & & & & & & \\
\hline Chromosomes & Average length $(\mu \mathrm{m})$ & $\%$ & $\mathrm{r}$ & $\mathrm{CI}$ & Classification & $\mathrm{N}$ \\
\hline I & $41.21 \pm 10.12 \mathrm{a}$ & $20.76 \mathrm{a}$ & $1.14 \pm 0.08$ & 46.94 & $\mathrm{~m}$ & \\
II & $36.64 \pm 8.88 \mathrm{~b}$ & $18.48 \mathrm{~b}$ & $1.13 \pm 0.07$ & 46.98 & $\mathrm{~m}$ & 48 \\
III & $21.53 \pm 5.56 \mathrm{c}$ & $10.75 \mathrm{c}$ & $4.91 \pm 0.60$ & 12.20 & $\mathrm{t}$ & \\
\hline
\end{tabular}

${ }^{1}$ The comparisons of chromosomal lengths and the relative lengths (\%) were made by means of one-way ANOVA. Different letters indicate significant differences $(\mathrm{p}<0.05)$ adjusted by Bonferroni.

and $P$. curvatus $\left(F_{2,123}=8.68, \mathrm{p}=0.0004\right)$. Chromosome II in $P$. nocens was also larger than in $P$. curvatus $\left(F_{2,123}=5.86, \mathrm{p}=0.0039\right)$, whereas in $P$. tricuspis it was of intermediate length. Finally, chromosome III was smaller in $P$. nocens than in $P$. tricuspis and $P$. curvatus $\left(F_{2,123}=29.14, \mathrm{p}<0.0001\right)$ (Table 2$)$.

Different banding techniques were applied in order to reveal heterochromatin and analyze its location and composition. DAPI and $\mathrm{CMA}_{3}$ sequential fluorescent banding did not reveal any regions either in AT rich (DAPI bright) or $\mathrm{GC}$ rich $\left(\mathrm{CMA}_{3}\right.$ bright) for any chromosome pair in any of the three species (Figure $1 \mathrm{c}-\mathrm{f}$ ). After C-banding treatment, slides were stained with DAPI, allowing a better analysis of the $\mathrm{C}$-heterochromatin pattern (Figure 2). C positive heterochromatin was scarce in all species, with a small $\mathrm{C}$ positive $(\mathrm{C}+)$ band in the long arm (q) of chromosome II and a completely $\mathrm{C}$ negative (C-) chromosome I (Figure 2a-f). "Somatic pairing" was evident from prophase up to meta-

Table 2 - Comparisons of total chromosomal lengths (TCL) and relative lengths (\%) among the Pseudacteon species analyzed.

\begin{tabular}{lcccc}
\hline \multirow{2}{*}{ Species } & \multirow{2}{*}{ TCL $(\mu \mathrm{m})^{1}$} & \multicolumn{3}{c}{$\%$} \\
\cline { 3 - 5 } & & $\mathrm{I}$ & $\mathrm{II}$ & $\mathrm{III}$ \\
\hline P. curvatus & $225.31 \pm 70.74 \mathrm{~A}$ & $19.96 \mathrm{~B}$ & $17.75 \mathrm{~B}$ & $12.29 \mathrm{~A}$ \\
P. tricuspis & $220.11 \pm 54.69 \mathrm{AB}$ & $19.88 \mathrm{~B}$ & $18.07 \mathrm{AB}$ & $12.05 \mathrm{~A}$ \\
P. nocens & $198.45 \pm 46.01 \mathrm{~B}$ & $20.76 \mathrm{~A}$ & $18.48 \mathrm{~A}$ & $10.75 \mathrm{~B}$ \\
\hline
\end{tabular}

${ }^{1}$ The comparisons of the total chromosomal lengths (TCL) and the relative lengths (\%) were analyzed by means of one-way ANOVA. Different letters indicate significant differences $(\mathrm{p}<0.05)$ adjusted by Bonferroni. phase (Figure 2a, d-i), but was lost during anaphase (Figure $2 \mathrm{~b}-\mathrm{c})$. The three species varied as to the $\mathrm{C}$-banding pattern in chromosome III. Thus, in P. curvatus a $\mathrm{C}+$ band present in the short arm (p) extended over $81 \%$ of its length (Figure 2a-c). In P. tricuspis, a C+ band observed in the long (q) arm near the centromere corresponded to approximately $4 \%$ of its length (Figure $2 \mathrm{~d}-\mathrm{e}$ ). Finally, the telocentric pair in $P$. nocens was completely C- (Figure $2 \mathrm{f}$ ).

Silver impregnation revealed only one nucleolus in interphase nuclei and two signals in early prophase cells in the three species. However, no positive results were obtained in metaphase chromosomes (Figure 3). In situ hybridization with the $18 \mathrm{~S}$ rDNA probe on metaphase cells showed a single hybridization signal in chromosome II in the three species at a location similar to that of the $\mathrm{C}+$ band (Figure 2g-i; Figure 4). This suggests that in the three Pseudacteon species a single cluster of rRNA genes is located in the long arm (q) of chromosome II near the centromere.

\section{Discussion}

The Pseudacteon species analyzed presented $2 \mathrm{n}=6$, with chromosomes I and II being metacentric and chromosome III subtelocentric in P. curvatus and P. tricuspis but telocentric in $P$. nocens. Total chromosome length (TCL) varied among Pseudacteon species, with $P$. curvatus $\geq P$. tricuspis $\geq P$. nocens, probably representing variations in DNA content that do not affect chromosome morphology. A similar situation has been reported in other dipteran fami- 

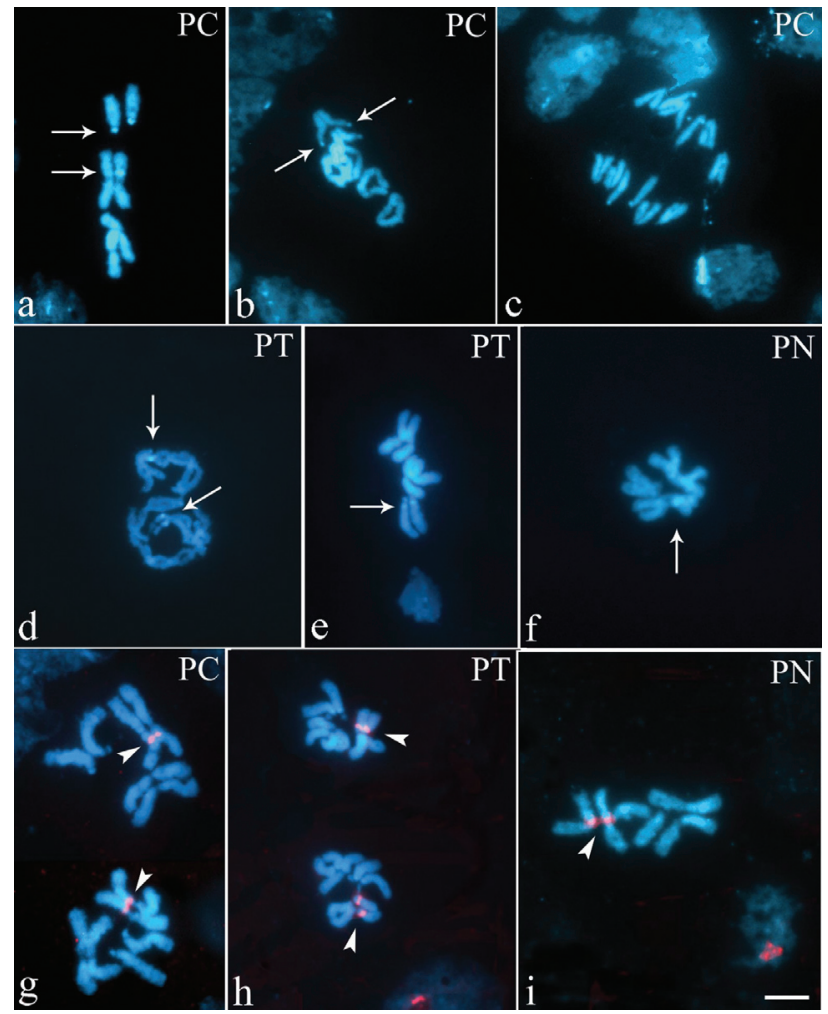

Figure 2 - Somatic mitosis of Pseudacteon curvatus (a-c, g), P. tricuspis (d-e, h) and $P$. nocens (f,i) after $\mathrm{C}$ banding (a-f) and in situ hybridization with a $18 \mathrm{~S}$ rDNA probe (g-i). At the top right-hand corner the names of species are indicated as $\mathrm{PC}=P$. curvatus, $\mathrm{PT}=P$. tricuspis, and $\mathrm{PN}=P$. nocens. Arrows (a-f) indicate blocks of heterochromatin and head arrows (g-i), rDNA sites. $\mathrm{Bar}=10 \mu \mathrm{m}$.

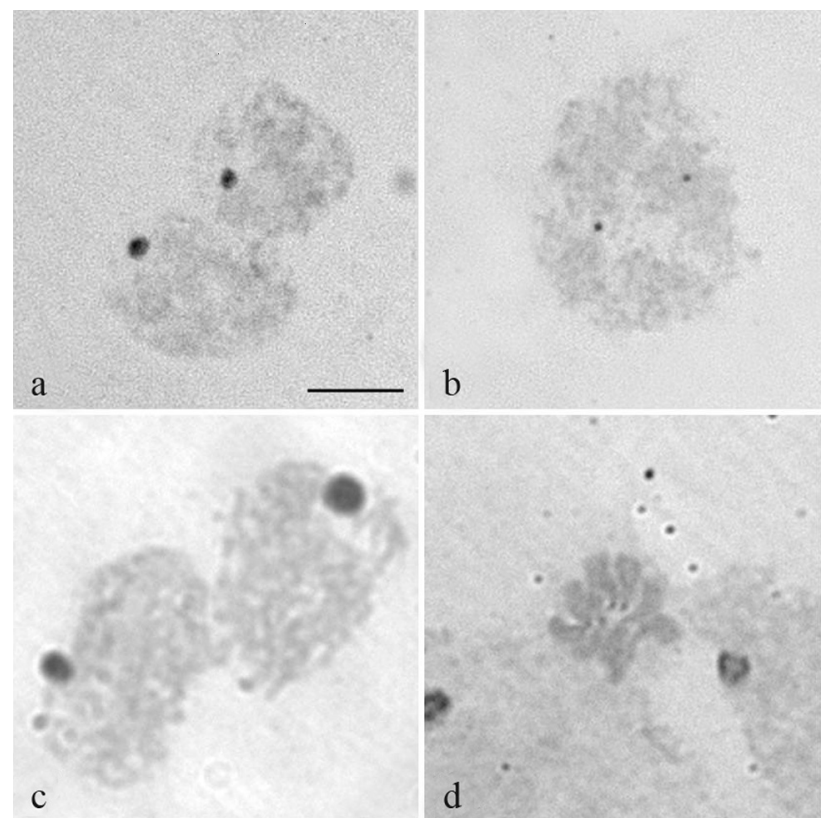

Figure 3 - Interphase nuclei of $P$. curvatus (a) and $P$. tricuspis (b), and the early prophase (c) in which one nucleolus was observed after silver nitrate NOR banding. d) Metaphase of P. tricuspis. No Ag-NOR band was detected on the condensed chromosomes. Bar $=10 \mu \mathrm{m}$. lies (Rafael and Tadei, 1998; Parise-Maltempi and Avancini, 2001; Selivon et al., 2005).

Heterochromatin content was very scarce in these Pseudacteon species. Chromosome I was completely C-, with a single $\mathrm{C}+$ band situated at the location of the $18 \mathrm{~S}$ rDNA hybridization signal on chromosome II. Major differences were observed in chromosome III, with a $\mathrm{C}+$ band in the p-arm of the subtelocentric pair in P. curvatus and the q-arm in $P$. tricuspis, although this was absent in the telocentric pair of $P$. nocens (Figure 4). The divergence between the former two species could be explained by pericentric inversion in chromosome III during their evolutionary history (Figure 5). Its absence in $P$. nocens suggests that it could have diverged before the differentiation of $P$. tricuspis and $P$. curvatus. Furthermore, the smaller size of chromosome III in P. nocens, as compared to the other two species, could be explained by the absence of a heterochromatin block. Although it would be necessary to analyze other Pseudacteon species, we propose here a possible hypothesis on karyotype evolution within the genus. We propose that after the divergence of $P$. nocens, and through the acquisition of heterochromatin, there was an increase in DNA across the genome of the ancestor of the other two species, but principally in chromosome III. In spite of the fragmented and unresolved phylogenies of some Pseudacteon species (Kronforst et al., 2007; Calcaterra et al., 2008), several conclusions support our hypothesis. The recent common ancestor of $P$. nocens is different from the most recent common ancestor of $P$. curvatus and $P$. tricuspis (Calcaterra et al., 2008), and phylogenies based on the mitochondrial genes Cytochrome Oxidase I and II and the nuclear gene Wingless (Kronforst et al., 2007) suggest that $P$. tricuspis could have derived from the ancestor from which $P$. curvatus diverged.

In reference to the studied Pseudacteon species, AgNOR banding revealed the presence of one nucleolus but not on metaphase chromosomes. Similar observations have been reported in other dipterans in which results from silver staining were unsatisfactory, and only centromeric cores could be differentiated (Motara et al., 1985; Wallace and Newton, 1987; Bedo and Webb, 1989; Marchi and Pili, 1994).

Cytogenetic characterization of Pseudacteon species failed to reveal morphologically differentiated sex chromosomes. The only other two species in the Phoridae in which cytogenetical data has come under analysis were Megaselia scalaris and M. spiracularis. Accordingly, both possess the same diploid number $2 \mathrm{n}=6$ and a similar chromosome morphology, with two metacentric and one telocentric chromosomes (Mainx, 1964). In this genus sex determination depends on the presence of a single Maleness factor M that triggers off male development (Mainx, 1964; Willhoeft and Traut, 1990; Traut and Wollert, 1998; Traut et al., 1999). Through molecular cytogenetic techniques and molecular markers it has been established that the chromo- 
a)

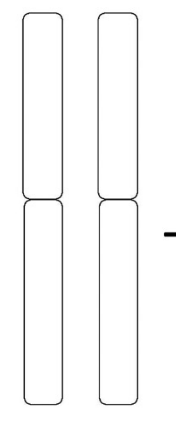

I

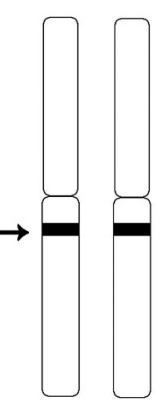

II b)

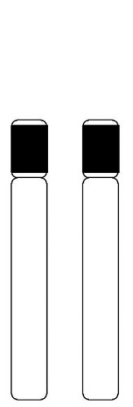

III

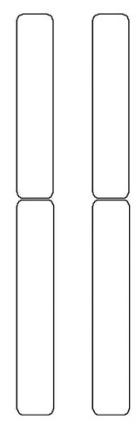

I

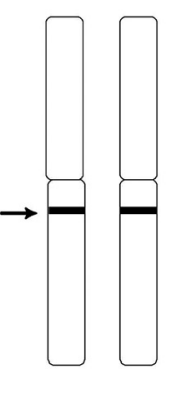

II

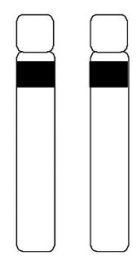

III c)

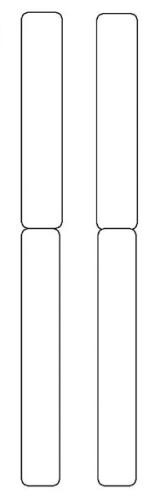

I

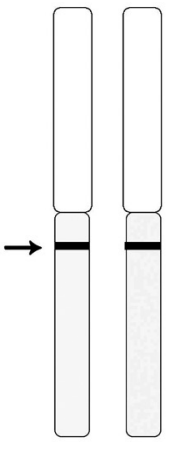

II

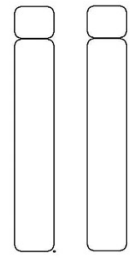

III

Figure 4 - Idiograms of Pseudacteon curvatus (a), P. tricuspis (b) and P. nocens (c). C-bands are shown as black segments, and arrows point out the location of the hybridization signal corresponding to18S rDNA.

somes $\mathrm{X}$ and $\mathrm{Y}$ in Megaselia are in a very early state of molecular differentiation (Traut, 1994).

In most of the studied Pseudacteon species, the sex of the offspring seems to be facultatively determined by the size of the host, with females emerging from the larger ones (Morrison et al., 1999; Folgarait et al., 2005a, 2006). From an evolutionary point of view, this makes sense since 1) fire-ant workers are highly variable in size (Tschinkel et al., 2003), 2) female flies have a higher fitness if they emerge from larger hosts, exhibiting a higher efficiency in development and larger sizes (Chirino, Gilbert, Folgarait, unpublished), and 3) females emerge from a narrower range of ant-sizes than males (Folgarait et al., 2005a, 2006; Chirino, Gilbert, Folgarait, unpublished). However, in two small species, P. cultellatus Borgmeier (Folgarait et al., 2002) and $P$. curvatus (Chirino et al., 2009), females and males develop in similar-sized hosts, and emerged adults are not sexually dimorphic in size, so that the above mentioned pattern is difficult to detect. The number of different species of Pseudacteon that develop on S. invicta exceeds the diversity observed in other ants (Disney, 1994). This diversity could be influenced by Solenopsis size polymorphism since there is a correlation between the sizes of both parasitoid and host (Morrison et al., 1997). Different Pseudacteon
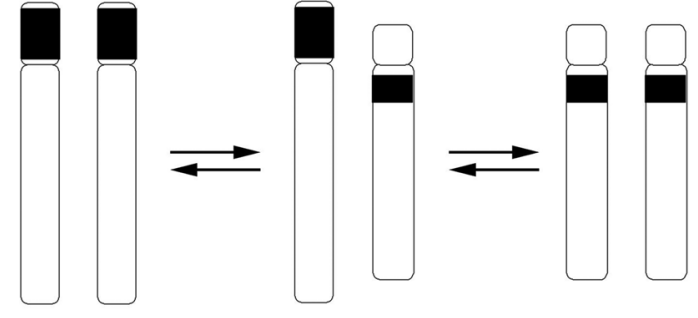

P. tricuspis
Figure 5 - Hypothesized karyotype evolution in Pseudacteon curvatus and $P$. tricuspis. Differences in chromosome III can be explained by pericentric inversion, although it is not possible to determine the direction of evolutionary change. species oviposit at different times during the day, at different locations (close to mounds or the foraging trails of ants) and during different seasons. $P$. nocens in particular is crepuscular and abundant in shady conditions, but $P$. curvatus and $P$. tricuspis are more abundant at midday and in sunny conditions (Folgarait et al., 2007a; 2007b). Furthermore, $P$. curvatus mainly attacks small workers (Chirino et al., 2009), P. tricuspis larger ants (Morrison et al., 1997), and $P$. nocens, medium-sized ones. Finally, $P$. tricuspis females exhibit competitive, aggressive and territorial behaviors, which are not observed in either P. curvatus or P. nocens. In this work we have shown that the well-known differences among $P$. curvatus, $P$. nocens and $P$. tricuspis as regards size, morphology, behavior and phylogenetic relations are also reflected in their karyotypes.

The exact mechanism of sex determination in Pseudacteon flies is perplexing (Porter, 1998). Environmental sex determination (ESD) has been suggested as a possible mechanism for the observed pattern (Morrison et al., 1999). Typically, taxa having non-differentiated sex chromosomes usually show labile sex-determination, and sex can be determined by environmental stimuli (Solari, 1994). Our demonstration of non-differentiated sex chromosomes in Pseudacteon phorids is thus consistent with the earlier suggestion of environmental sex determination in these parasitoid flies, and should encourage further investigation of how sex is determined in this genus.

\section{Acknowledgments}

We thank Lic. Gloria Albioni Montenegro for her help in several aspects of the experiments. This research was supported by grants from the Programa de Investigación en Interacciones Biológicas (PPUNQ-0340/03), Universidad Nacional de Quilmes; the R.J. Kleberg \& H.C. Kleberg Foundation; Universidad de Buenos Aires (X164) and PICT 2007-00635 of ANPCyT. M.G.Ch., P.J.F. and 
A.G.P. thank the Consejo Nacional de Investigaciones Científicas y Técnicas (CONICET).

\section{References}

Baruffi L, Damiani G, Guglielmino C, Bandi C, Malacrida A and Gasperi G (1995) Polymorphism within and between population of Ceratitis capitata. Comparison between RAPD and Multilocus enzyme electrophoresis data. Heredity 74:524537.

Bedo DG and Webb GC (1989) Conservation of nucleolar structure in polytene tissues of Ceratitis capitata (Diptera, Tephritidae). Chromosoma 98:443-449.

Brown BV, Folgarait PJ and Gilbert L (2003) A new species of Pseudacteon attacking solenopsis fire ants (Hymenoptera, Formicidae) in Argentina. Sociobiology 41:685-688.

Calcaterra LA (2007) Pseudacteon calderensis, a new fly species (Diptera, Phoridae) attacking the fire ants Solenopsis interrupta (Hymenoptera, Formicidae) in northwestern Argentina. Ann Entomol Soc Am 100:470-473.

Calcaterra LA, Delgado A and Tsutsui ND (2008) Activity patterns and parasitism rates of fire ant-decapitating flies (Diptera, Phoridae, Pseudacteon spp.) in their native Argentina. Ann Entomol Soc Am 101:539-550.

Cevallos VE and Nation JL (2004) Chromosomes of the Caribbean fruit fly (Diptera, Tephritidae). Fla Entomol 87:361364.

Chirino MG, Gilbert LE and Folgarait PJ (2009) Behavior and development of Pseudacteon curvatus (Diptera, Phoridae) varies according to the social form of its host Solenopsis invicta (Hymenoptera, Formicidae) in its native range. Environ Entomol 38:198-206.

Disney RHL (1994) Scuttle Flies: The Phoridae. Chapman \& Hall, London, 480 pp.

Folgarait PJ, Bruzzone OA and Gilbert LE (2002) Development of Pseudacteon cultellatus (Diptera, Phoridae) on Solenopsis invicta and Solenopsis richteri fire ants (Hymenoptera, Formicidae). Environ Entomol 31:403-410.

Folgarait PJ, Chirino MG, Wilson Patrock RJ and Gilbert LE (2005a) Development of Pseudacteon obtusus (Diptera, Phoridae) on Solenopsis invicta and Solenopsis richteri fire ants (Hymenoptera, Formicidae). Environ Entomol 34:308316.

Folgarait PJ, Bruzzone OA, Porter SD, Pesquero MA and Gilbert LE (2005b) Biogeography and macroecology of phorid flies that attack fire ants in southeastern Brazil and Argentina. J Biogeogr 32:353-367.

Folgarait PJ, Wilson Patrock RJ and Gilbert LE (2006) Development of Pseudacteon nocens (Diptera, Phoridae) on Solenopsis invicta and Solenopsis richteri fire ants (Hymenoptera, Formicidae). J Econ Entomol 99:295-307.

Folgarait PJ, Patrock RJW and Gilbert LE (2007a) Associations of fire ant phorids and microhabitats. Environ Entomol 36:731-742.

Folgarait PJ, Patrock RJW and Gilbert LE (2007b) The influence of ambient conditions and space on the phenological patterns of a Solenopsis phorid guild in an arid environment. Biol Control 42:262-273.

Fuková I, Nguyen P and Marec F (2005) Codling moth cytogenetics: Karyotype, chromosomal location of rDNA, and molecular differentiation of sex chromosomes. Genome 48:1083-1092.

Gilbert F and Jervis M (1998) Functional, evolutionary and ecological aspects of feeding-related mouthpart specializations in parasitoid flies. Biol J Linn Soc 63:495-535.

Howell WM and Black AD (1980) Controlled silver-staining of nucleolus organizer regions with a protective colloidal developer: A 1-step method. Experientia 36:1014-1015.

Kronforst MR, Folgarait PJ, Patrock RJW and Gilbert LE (2007) Genetic differentiation between body size biotypes of the parasitoid fly Pseudacteon obtusus (Diptera, Phoridae). Mol Phylogenet Evol 43:1178-1184.

Levan A, Fredga K and Sandberg A (1964) Nomenclature for centromeric position on chromosomes. Hereditas 52:201220.

Mainx F (1964) The genetics of Megaselia scalaris Loew (Phoridae): A new type of sex determination in Diptera. Am Nat 98:415-430.

Marchi A and Pili E (1994) Ribosomal RNA genes in mosquitoes: Localization by fluorescence in situ hybridization (FISH). Heredity 72:599-605.

Mescher MC, Ross KG, Shoemaker DD, Keller L and Krieger MJB (2003) Distribution of the two social forms of the fire ant Solenopsis invicta (Hymenoptera, Formicidae) in the native South American range. Ann Entomol Soc Am 96:810817.

Morrison LW and Porter SD (2006) Post-release host-specificity testing of Pseudacteon tricuspis, a phorid parasitoid of Solenopsis invicta fire ants. Biocontrol 51:195-205.

Morrison LW, Dall'aglio-Holvorcem CG and Gilbert L (1997) Oviposition behavior and development of Pseudacteon flies (Diptera, Phoridae), parasitoids of Solenopsis fire ants (Hymenoptera, Formicidae). Environ Entomol 26:14-22.

Morrison LW, Porter SD and Gilbert LE (1999) Sex ratio variations as a function of host size in Pseudacteon flies (Diptera, Phoridae), parasitoids of Solenopsis fire ants (Hymenoptera, Formicidae). Biol J Linn Soc 66:257-267.

Motara MA, Pathak S, Satya-Prakash KL and Hsu TC (1985) Argentophilic structures of spermatogenesis in the yellow fever mosquito. J Hered 76:295-300.

Parise-Maltempi PP and Avancini RMP (2000) Cytogenetics of the neotropical flesh fly Pattonella intermutans (Diptera, Sarcophagidae). Genet Mol Biol 23:563-567.

Parise-Maltempi PP and Avancini RMP (2001) C-banding and FISH in chromosomes of the blow flies Chrysomia megacephala and Chrysomia putoria (Diptera, Calliphoridae). Mem Inst Oswaldo Cruz 96:371-377.

Patrock RJW, Porter SD, Gilbert LE and Folgarait PJ (2009) Distributional patterns of Pseudacteon associated with the Solenopsis saevissima complex in South America. J Insect Sci (in press).

Porter SD (1998) Biology and behavior of Pseudacteon decapitating flies (Diptera, Phoridae) that parasitize Solenopsis fire ants (Hymenoptera, Formicidae). Fla Entomol 81:292-308.

Porter SD and Pesquero MA (2001) Illustrated key to Pseudacteon decapitating flies (Diptera, Phoridae) that attack Solenopsis saevissima complex fire ants in South America. Fla Entomol 90:135-138.

Porter SD, Nogueira de Sá LA and Morrison LW (2004) Establishment and dispersal of the fire ant decapitating fly 
Pseudacteon tricuspis in North Florida. Biol Control 29:179-188.

Porter SD, Pesquero MA, Campiolo S and Fowler HG (1995) Growth and development of Pseudacteon phorid fly maggots (Diptera, Phoridae) in the head of Solenopsis fire ant workers (Hymenoptera, Formicidae). Environ Entomol 24:475-479.

Rafael MS and Tadei WP (1998) Metaphase karyotypes of Anopheles (Nyssorhynchus) darlingi Root and A. (N.) nuneztovari Gabaldón (Diptera, Culicidae). Genet Mol Biol 21:351-354.

Rebagliati P, Papeschi AG and Mola LM (2003) Meiosis and fluorescent banding in Edessa meditabunda and $E$. rufomarginata (Heteroptera, Pentatomidae, Edessinae). Eur J Entomol 100:11-18.

Ross KG, Krieger MJB, Keller L and Shoemaker DD (2008) Genetic variation and structure in native populations of the fire ant Solenopsis invicta: Evolutionary and demographic implications. Biol J Linn Soc 92:541-560.

Sahara K, Marec F and Traut W (1999) TTAGG telomeric repeats in chromosomes of some insects and other arthropods. Chromosome Res 7:449-460.

Selivon D, Perondini ALP and Rocha D (2005) Karyotype characterization of Anastrepha fruit flies (Diptera, Tephritidae). Neotrop Entomol 34:273-279.

Solari AJ (1994) Sex chromosomes and sex determination in vertebrates. CRC Press, Boca Raton, 336 pp.

Steinemann S and Steinemann M (2005) Retroelements: Tools for sex chromosome evolution. Cytogenet Genome Res 110:134-143.

Sumner AT (1972) A simple technique for demonstrating centromeric heterochromatin. Exp Cell Res 75:304-306.

Thead LG, Vogt JT and Streett DA (2005) Dispersal of the fire ant decapitating fly, Pseudacteon curvatus (Diptera, Phoridae) in northeast Mississippi. Fla Entomol 88:214-216.
Traut W (1976) Pachytene mapping in the female silkworm Bombyx mori L. (Lepidoptera). Chromosoma 58:275-284.

Traut W (1994) Sex determination in the fly Megaselia scalaris, a model system for primary steps of sex chromosome evolution. Genetics 136:1097-1104.

Traut W and Willhoeft U (1990) A jumping sex determining factor in the fly Megaselia scalaris. Chromosoma 99:407-412.

Traut W and Wollert B (1998) An X/Y DNA segment from an early stage of sex chromosome differentiation in the fly Megaselia scalaris. Genome 41:289-294.

Traut W, Sahara K, Otto TD and Marec F (1999) Molecular differentiation of sex chromosomes probed by comparative genomic hybridization. Chromosoma 108:173-180.

Tschinkel WR, Mikheyev AS and Storz SR (2003) Allometry of workers of the fire ant, Solenopsis invicta. J Insect Sci 3:e2.

Wallace AJ and Newton ME (1987) Heterochromatin diversity and cyclic responses to selective silver staining in Aedes aegypti (L.). Chromosoma 95:89-93.

White MJD (1973) Animal Cytology and Evolution. $3^{\text {rd }}$ edition. Cambridge University Press, London, 961 pp.

Willhoeft U and Traut W (1990) Molecular differentiation of the homomorphic sex chromosomes in Megaselia scalaris (Diptera) detected by random DNA probes. Chromosoma 99:237-242.

\section{Internet Resources}

MicroMeasure Web site, http://www.colostate.edu/Depts/Biology/MicroMeasure, for MicroMeasure for Windows, version 3.3 .

Associate Editor: Yatiyo Yonenaga-Yassuda

License information: This is an open-access article distributed under the terms of the Creative Commons Attribution License, which permits unrestricted use, distribution, and reproduction in any medium, provided the original work is properly cited. 